\title{
What is the meaning of becoming PubMed Central journal?
} KJME

\section{Sun Huh}

\author{
Department of Parasitology and Institute of Medical Education, Hallym University College of Medicine, Chuncheon, \\ Korea
}

On July 20, 2016, I received a message from PubMed Central (PMC) that the Korean Journal of Medical Education shifted to PMC live beginning with the March 2016 issue. On July 24, 2016, the June issue appeared in PMC. The application to PMC was submitted on December 1, 2015. The journal passed the scientific quality evaluation on March 3, 2016. After delivering PMC XML files, the technical quality evaluation was accepted on July 21, 2016 (United States Eastern Standard Time). It took roughly 8 months for the Korean Journal of Medical Education to appear in PMC once the application form had been submitted.

I was delighted to hear from PMC because this recognition represents a milestone that enables cooperation and competition with nine other open access PMC journals focused on medical education: Advances in Medical Education and Practice, BMC Medical Education, International Journal of Medical Education, Journal of Advances in Medical Education \& Professionalism, Journal of Educational Evaluation for Health Professions, Journal of Graduate Medical Education, Journal of Undergraduate Neuroscience Education, Me- dical Education Online, and Perspectives on Medical Education.

The Korean Journal of Medical Education changed its language format to English beginning with the first issue of 2016 for a broader circulation of the text of the journal and solicitation of manuscripts from all over the world. Although it has been indexed and searchable in PubMed since its inclusion in Medline in March 2015, the full text in PMC is another platform for the journal to be propagated to the world. Abstracts, full texts, and references are searchable through PMC; therefore, there is a greater likelihood that more hits will be received from researchers.

Recognition as a PMC journal gives a definitive boost to the journal's reputation, as well as evidence of its financial stability. Without an investment in the technological production of PMC XML files, it is not possible to be added to PMC. Currently, there is no article processing charge for submissions to the journal. The publisher's full support for journal publishing is the basis of its designation as a PMC journal. Full-text PMC XML, now called Journal Article Tag Suite (JATS) XML,
Received: July 26, 2016 • Revised: August 5, 2016 • Accepted: August 5, 2016 Corresponding Author: Sun Huh (http://orcid.org/0000-0002-8559-8640) Department of Parasitology and Institute of Medical Education, Hallym University College of Medicine, 1 Hallimdaehak-gil, Chuncheon 24252, Korea Tel: +82.33.248.2652 Fax: +82.33.241.1672 email: shuh@hallym.ac.kr
Korean J Med Educ 2016 Sep; 28(3): 265-267.

http://dx.doi.org/10.3946/kjme.2016.38

eISSN: 2005-7288

(C) The Korean Society of Medical Education. All rights reserved. This is an open-access article distributed under the terms of the Creative Commons Attribution Non-Commercial License (http:// creativecommons.org/licenses/by-nc/3.0/), which permits unrestricted non-commercial use, distribution, and reproduction in any medium, provided the original work is properly cited. 
is mandatory for most medical journals in Korea regardless of journal language. High-performing information technology in Korea has made it easy for medical societies to produce JATS XML files at reasonable costs. As of July 2016, 118 PMC journals were from Korea. This number places Korea fourth in rankings by country. The United States ranks first with 533 journals; the United Kingdom is second with 516, and India is third with 133 (Fig. 1). There are many English-language open access or free access medical journals worldwide. Society journals are usually open access or free access, although a few have been added to PMC. It is noteworthy that all English-language medical journals in Korea either have been added to PMC or are in the midst of the application process. Such recognition is evidence of the merit and quality of Korea's scholarly journals. In Korea, no medical journal is published by a commercial company; rather, all journals are published by societies or nonprofit organizations. Currently, there are 48 PMC journals from China and 32 from Japan; together, these two countries publish more medical journals than Korea does, but Korea has more PMC journals. I anticipate that more medical journals from Asia will be added to PMC upon adoption of full-text JATS XML production.

Recently, passing the evaluation step of scientific qualification has not been easy for applicant journals. In fact, some journals from Korea have been advised that they will need to be reevaluated for application in a year. The following information should be described precisely on a journal's website: editorial policies, editorial and peer review processes, advertising policies for print and web publications, statements concerning conflict of interest, human and animal rights, informed consent for publications, and compliance with International $\mathrm{Com}^{-}$ mittee of Medical Journal Editors (ICMJE) recommendations. As for the Korean Journal of Medical Education, these various information items are thoroughly $\mathrm{de}^{-}$ scribed.

Achieving the status as a PMC journal is a milestone to be circulated internationally. I appreciate the PMC staff members for their sincere and thorough evaluation of the scientific and technical quality of the journal.

Fig. 1. Number of PubMed Central (PMC) Journals as of July 2016 by Country Based on the United States National Library of Medicine Catalog ${ }^{a)}$

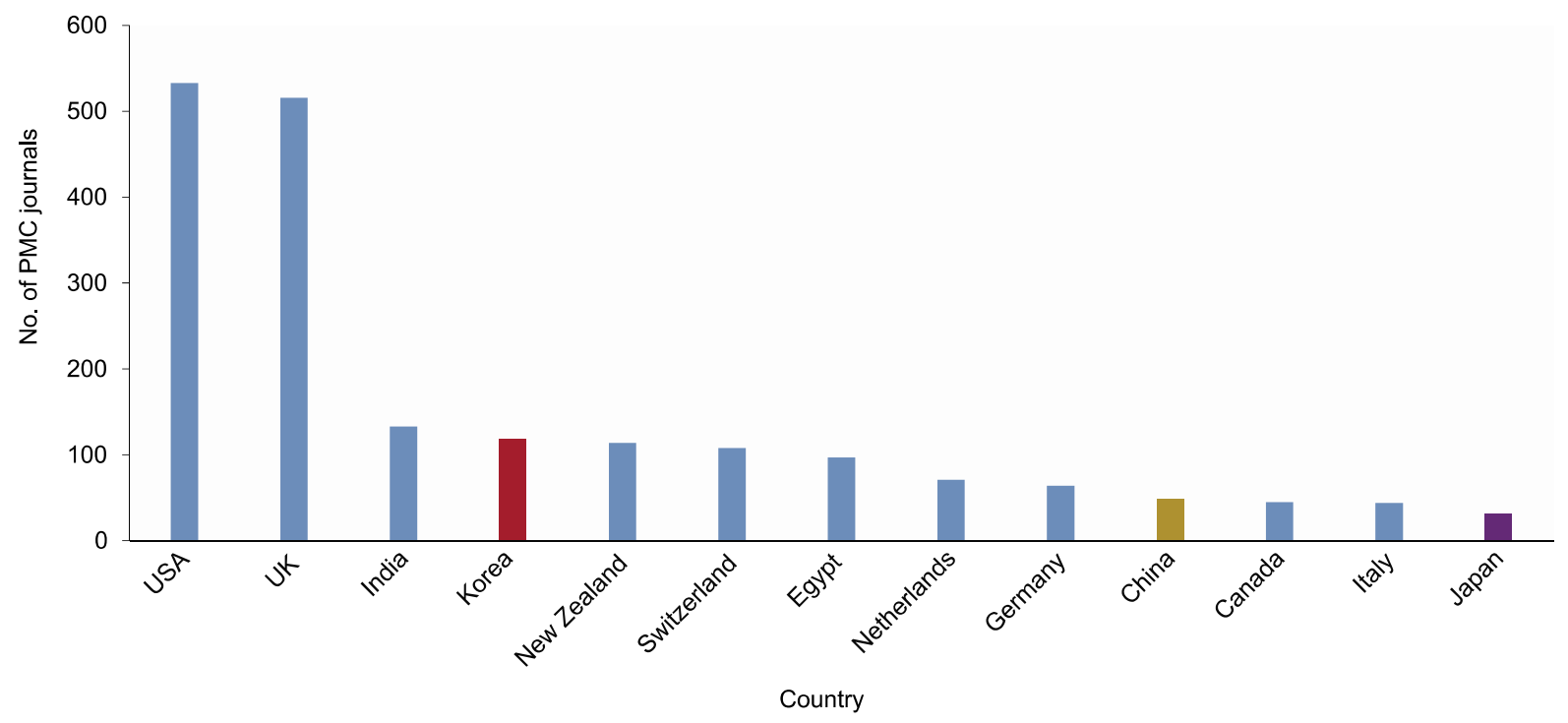

${ }^{a)}$ Available from: http://www.ncbi.nlm.nih.gov/nlmcatalog. 
Additionally, the engineers and XML tagging staffs of M2community Co. are to be commended for the high quality of their work. I also appreciate all members of the Korean Society of Medical Education, as well as the readers, authors, and reviewers of the journal who have contributed to this distinguished designation as a PMC journal.
ORCID: Sun Huh: http://orcid.org//0000-0002-8559-8640

Acknowledgements: None.

Funding: None.

Conflicts of interest: Sun Huh has been a Deputy Editor of the Korean Journal of Medical Education since 2009 and had been an Editorial Board member from 2007 to 2008. M2community Co. is an information technology company that has worked for the journal since 2013. 